\title{
Farmers Perception of Low Soil Fertility and Hybrid Maize and the Implications in Plant Breeding
}

\author{
Priscilla F. Ribeiro ${ }^{1}$, Baffour Badu-Apraku ${ }^{2}$, Vernon E. Gracen ${ }^{3}$, Eric Y. Danquah ${ }^{3}$, Manfred B. Ewool ${ }^{1}$, Charles \\ Afriyie-Debrah $^{1} \&$ Benedicta N. Frimpong $^{1}$ \\ ${ }^{1}$ CSIR-Crops Research Institute, Ghana \\ ${ }^{2}$ International Institute Tropical Agriculture, Ibadan, Nigeria \\ ${ }^{3}$ West Africa Centre for Crop Improvement, University of Ghana, Legon, Ghana \\ Correspondence: Priscilla F. Ribeiro, CSIR-Crops Research Institute, P.O. Box 3785, Kumasi, Ghana. Tel: \\ 233-244-723-713. E-mail: prisboat@yahoo.com
}

Received: November 29, 2016 Accepted: January 4, 2017 Online Published: January 25, 2017

doi:10.5539/sar.v6n2p1 URL: http://dx.doi.org/10.5539/sar.v6n2p1

\begin{abstract}
In spite of efforts by national and international scientists to improve crop productivity, varieties of crops grown in Africa have low productivity. Varieties improved for yield have had low adoption rates among small scale farmers. Productivity of maize remains low in the smallholder sector because the crop continues to be grown under stress-prone environments and with limited resources. Participatory Rural Appraisal (PRA) tools, including two focus group discussions and interviews with 120 individual farmers were conducted in Wenchi and Ejura-Sekyedumase districts in Ghana to determine maize production constraints, assess farmers' perceptions of low soil fertility in maize production and their coping strategies for the control of low soil fertility. Opportunities for breeding new maize varieties with tolerance to low soil fertility and improving farmers' perception on adoption and utilisation of maize hybrids were also examined. Results from interviews revealed that low soil fertility, drought, diseases and insect pests are the dominant constraints in maize productivity in the two districts. Farmers in the study area also have preference for low soil nitrogen (low N) tolerant, drought tolerant, disease and pest resistant varieties that require lower inputs. They prefer maize varieties which produce slender cobs that are light in weight with lots of grain. The farmers lack knowledge about hybrids but are willing to adopt maize hybrids that are tolerant to low $\mathrm{N}$.
\end{abstract}

Keywords: drought, hybrid maize, low soil nitrogen, participatory rural appraisal

\section{Introduction}

The Ghanaian economy and livelihood of its population heavily depend on agriculture. For this reason, efforts to sustain and improve the sector's productivity are extremely crucial to the country's economic development and also to the welfare of her people. Securing food and livelihood is inextricably linked to the exploitation of the natural resource base (land, water and forest). Soil degradation, mainly due to soil erosion and nutrient depletion, has become one of the most important environmental and economic problems in Ghana (Adu, 2012).

Soil fertility decline is a major biophysical factor challenging crop production in Ghana (Logah et al., 2010). The estimated annual loss of maize grain yield due to low N stress alone varies from 10 to 50\% (Wolfe et al., 1988; Logrono and Lothrop, 1997). Reducing losses caused by low soil N could increase maize productivity in Ghana and significantly contribute towards national food security and poverty alleviation. Furthermore, understanding the production constraints that farmers face, low soil fertility in particular could greatly assist in the design of an effective breeding programme that could incorporate tolerance to low soil $\mathrm{N}$ and also improve other agronomic traits as well. Hence, the inclusion of farmers' perceptions of low soil $\mathrm{N}$ varieties in the national maize breeding programs is essential.

More than 30 improved maize varieties have been released in Ghana between 1942 and 2014 (CRI library, 2015). Though these have been made available to farmers through agricultural extension personnel, maize productivity remains low. This may be attributed in part to low adoption of productivity-enhancing technologies including improved varieties and management practices, low use of purchased inputs, especially fertilizer, and lack of appropriate government policies (Ragasa et al., 2013). 
Participatory rural appraisals (PRAs) have been used worldwide to solicit farmers' views on various agricultural resource management options necessary to ensure household food security and improvement in their welfare (Odendo et al., 2002). Formal plant breeding approaches in the public sector have not been seeking input from farmers, as is evident in both the slow adoption rate of improved varieties by farmers and the poor performance of adopted varieties under low input conditions (Bänziger and Cooper, 2001). To improve the adoption rate and increase performance of adopted varieties, an assessment of attributes of maize varieties preferred by farmers and the socio-economic environment under which the farmers operate is critical. By integrating farmers' concerns and circumstances into agricultural research, researchers can develop technologies that would be more widely adopted, resulting in more productive, stable, equitable and sustainable agricultural systems. The objectives of this study were to:

i) Examine maize production constraints of farmers in Ghana.

ii) Assess farmers' perceptions of the problem of low soil fertility in maize production and their strategies for coping with low soil fertility.

iii) Evaluate their potential interest in new maize varieties with enhanced tolerance to low soil fertility and other important traits.

iv) Evaluate farmers' perceptions on adoption of hybrids.

\section{Methodology}

\subsection{Brief Description of Study Areas}

The PRA was carried out in two districts, Wenchi in the Brong Ahafo Region and Ejura-Sekyedumase in the Ashanti Region of Ghana. The EjuraSekyedumase district is located in the Northern part of Ashanti Region and the Wenchi district in the western part of Brong Ahafo Region. Both districts are located in the Forest-Savanna transition agro-ecological zone. The two districts are characterized by a bimodal rainfall pattern where the major season is between April and July and the minor season is between September and November. Hence there are two cropping seasons. The average annual rainfall is about 1,140 - 1,270 $\mathrm{mm}$ in Wenchi and 1,200 - 1,500 mm in Ejura-Sekyedumase. The temperatures in the districts range from $21^{0} \mathrm{C}-300^{\mathrm{C}}$. The major occupation in these districts is farming and maize is one of the main staple crops grown. Assisted by extension officers, three communities (villages) were chosen in each district based on the maize production volumes and accessibility and presence of maize related research activities. Akrobi $(07.743 \mathrm{~N}, 082.129 \mathrm{~W})$, Awisa $(07.81 \mathrm{~N}, 0.02 .11 \mathrm{~W})$ and Amposahkro $(07.86 \mathrm{~N}, 002.08 \mathrm{~W})$ were the three villages in the Wenchi district while those in the Ejura-Sekyedumase district were Adiembra $(07.43 \mathrm{~N}, 001.49 \mathrm{~W})$, Aframso $(07.31 \mathrm{~N}, 001.39 \mathrm{~W})$ and Teacherkrom $(07.33 \mathrm{~N}, 001.43 \mathrm{~W})$.

\subsection{Sampling Technique}

One hundred and twenty small-scale farmers were involved in the PRA study. They were identified by local agricultural officials and randomly selected without any bias towards age, gender, experience in farming or status in the community.

\subsection{Data Collection Procedure and Analysis}

The study used both qualitative and quantitative approaches to elicit data from maize farmers. The qualitative approaches employed key informant interviews and focus group discussions to draw collective responses from farmers. This was followed a formal survey using a structured interview schedule to collect information on farmers' perception on low soil nitrogen and coping strategies, awareness of hybrid maize varieties, constraints in maize production and preferred maize traits for breeding purposes. Data was analyzed using Statistical Package for Social Sciences (SPSS) version 16. Descriptive statistics such as frequency counts, percentages, and charts were used to describe the attributes of the variables collected.

\section{Results}

\subsection{Constraints to Maize Production}

Low soil fertility was identified as the most important constraint to maize production in all the villages (Figure. 1). This was followed by drought, pests and diseases. All the farmers interviewed described the symptoms of low soil fertility as yellowing of leaves, stunted growth and reduced yield, which is related to symptoms of low $\mathrm{N}$ or low $\mathrm{P}$ or both. In response to questions about the factors responsible for low soil fertility, ninety-eight percent of the farmers from all the villages identified continuous cropping on the same land as the main cause. They also identified lack of fertilizer application and lack of crop rotation activities as the second and third major causes (Figure. 2). In their opinion, excessive rainfall did not contribute significantly to low soil fertility in the 
locations.

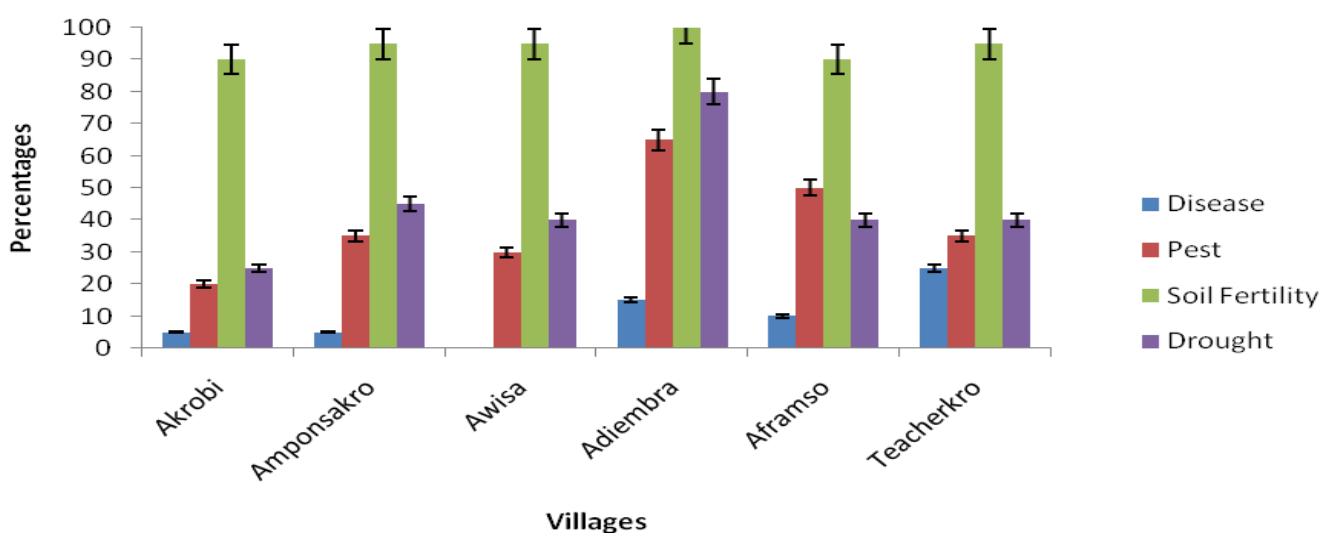

Figure 1. Constraints to maize production in the various villages

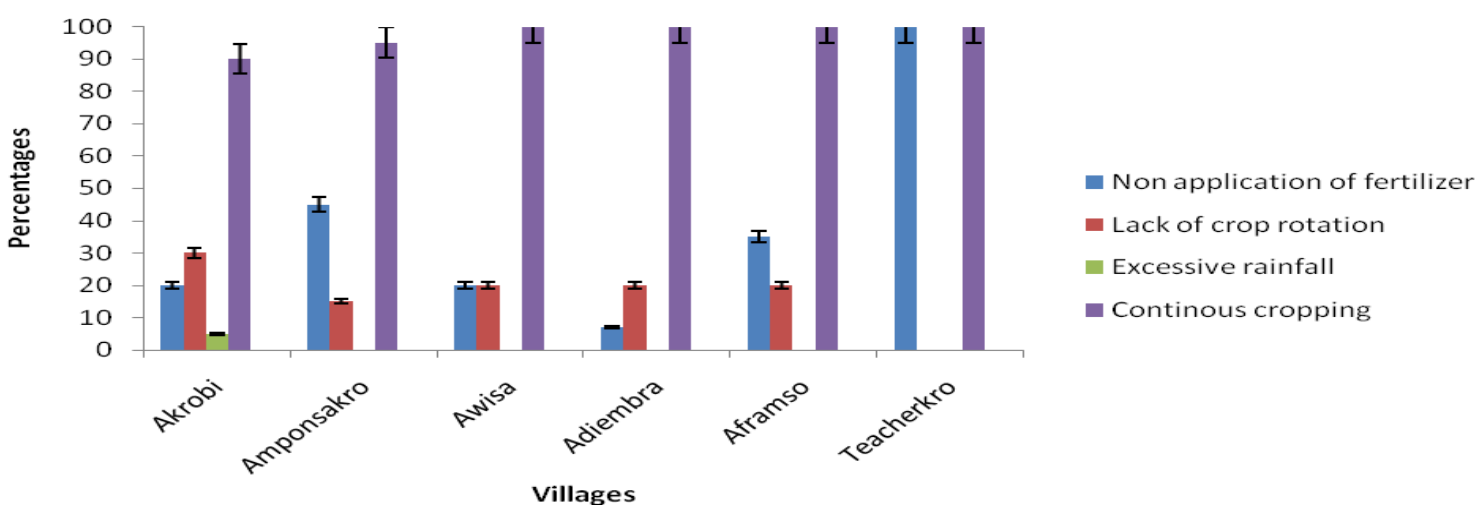

Figure 2. Causes of low soil fertility

\subsection{Management of Low Soil Fertility (Coping Strategies)}

The majority of the farmers (94\%) mentioned application of fertilizer as the most important method to replenish soil of low fertility (Fig. 4). Twenty-three percent of the farmers ranked crop rotation as an effective method for replenishing low soil fertility. Only 5\% of farmers mentioned fallowing as useful for managing fertility. Land rotation was not mentioned, as land is generally very scarce in the area.

\subsection{Fertilizer Use}

The majority of the farmers (90\%) purchase unsubsidized fertilizers, which they claim was very expensive. They indicated that, while the distance to agro-chemical stores is not a problem, availability of fertilizer during the period when it is needed most is a major challenge.

\subsection{Perception on Hybrids}

Ninety-five percent (95\%) of the farmers interviewed showed preference for local and improved open-pollinated variety (OPV) seeds over hybrid seeds because they believed that the former was high yielding and responded better to drought. Only $4.1 \%$ of the farmers interviewed had ever planted hybrid seed, although $25.8 \%$ had heard about it. The few farmers who grew hybrids testified to the high yielding characteristics and appreciable low soil fertility tolerance levels but $95.9 \%$ of the farmers still prefer to grow local OPVs because the seeds can be saved and recycled. Their major concern with hybrids was with the high cost of seeds. The $25.8 \%$ who had heard about hybrids confused them with improved OPV seeds.

\subsection{Willingness to Use Low N Tolerant Maize Varieties}

All the farmers showed interest in maize hybrids tolerant to low soil $\mathrm{N}$ but expressed reservations about the seed price. Most of the respondents were not willing to pay anything more than the existing market seed price of GHC4.40 per kilo (as at 2015). However, they indicated that they would only purchase the new hybrids if they had superior performance in on-farm trials. 


\section{Discussion}

Farmers identified low soil fertility, drought, pests and diseases as major production constraints impeding maize productivity in the smallholder sector. Of these low soil fertilities was the outstanding constraint. These constraints are common to the majority of small-scale farmers in sub-Saharan Africa (De Vries and Toenniessen, 2001; Odendo et al., 2002; Wekesa et al., 2003). Farmers identified leaf yellowing, stunted growth and reduced yield as symptoms characteristic of low soil fertility. Though farmers were not able to directly link to low soil fertility to vital soil nutrients including nitrogen, there is ample evidence in literature which links the two. For instance, Lafitte and Edmeades, (1994) posit that high yields for maize production is largely linked to utilization and uptake efficiency of Nitrogen, Phosphorus and Potassium, hence the encouragement for farmer to apply inorganic fertilizer in the absence of the organic alternative. The farmers have adopted a number of coping strategies to mitigate the problem of low soil fertility. Fertilizer application is the major method employed to replenish soil fertility. Lack of fertilizer application is a major cause of low soil fertility. This is consistent with the findings of Ragasa et al. (2013).

Apart from the high price of fertilizer, it is sometimes not readily available when needed. This means that low levels of fertilizer are applied which results in low yield. Farmers indicated that occasionally the government subsidy on fertilizers arrives quite late after planting activities were completed, making it not useful to them. Efforts at enhancing timely availability of subsidized fertilizers to farmers at the appropriate time are highly encouraged. These findings disagree with those of Ragasa et al. (2013) who observed that the fertilizer subsidy program may have encouraged farmers to use more fertilizer in their maize plots.

Some farmers in this study practice crop rotation with cowpea, cassava and groundnut. The farmers were aware that the crops used for the rotation could help fix nitrogen in the soil and hence improve soil fertility. This finding is consistent with those of Morris et al. (1999). Land rotation, however, is scarcely employed because land is scarce and very expensive to acquire.

Many of the participants of this study could not afford to purchase fertilizer and land. It is obvious, therefore, that cultivation of varieties tolerant to low soil fertility is the most practical and cost-effective means to manage low soil fertility.

Farmers demonstrated a lot of interest in new maize varieties. They are willing to adopt them if they have assurance that farmers' preferences have been incorporated and they are adapted to local farming conditions. This finding is consistent with those of Nkonya and Featherstone (2001), who reported that varieties with farmer preferred traits are easily adopted and confirmed that farmers' personal experiences influence what varieties they grow.

Farmer perception of hybrid seeds released in Ghana is that they do not possess their preferred characteristics compared to OPVs. Hence, there is generally low adoption of hybrid seeds for maize production in Ghana. This phenomenon may, in part, be attributed to lack of interest and / or knowledge of these varieties by the farmers. Lack of attention and promotion of hybrid varieties in Ghana are the most likely reasons for low uptake by farmers. The effect of low opinion of farmers about hybrid seeds could also be one of the reasons why Ghana remains far behind other African countries in hybrid adoption. For instance, more than 90 percent adoption of hybrid maize is observed in Zambia, Kenya, and Zimbabwe compared with only 3 percent in Ghana. (Tripp and Mensah-Bonsu 2013).

Though hybrid seeds offer many benefits, including greater yield, improved pest resistance, and better stress tolerance than OP varieties, to farmers who buy them year after year (Dogor, 2013), this research indicates that farmers may not invest in hybrid seeds for reasons included high prices of hybrid seed, non-availability of hybrid seed at local shops, belief that there is a high requirement of fertilizer for cultivation, small or no differences in yield when compared to local or improved varieties, poor storability and poor processing quality.

Hybrid seeds with potential to thrive and increase maize production in conditions such as low soil nitrogen is even more critical under the prevailing circumstances. It is a major game-changer with a potential to transform maize productivity in Africa in general and specifically in Ghana.

Farmers interviewed in this study area lacked knowledge about hybrids. For this reason, the need for education on the benefits of hybrids cannot be overemphasized. Farmers generally obtain information on fertilizers and other production matters from extension workers of MOFA. It is important that the extension and other agencies educate farmers on the importance and potential benefits of hybrids. Breeders need to collaborate with farmers at the initial stages of varietal development as suggested by Sperling $e t$ al. (2001). This would allow breeders to identify farmer-preferences in order to incorporate them into improved varieties developed for their specific 
areas.

\section{Conclusion and Implication}

The survey identified low soil fertility, drought, diseases and insect pests as major constraints to maize production in the study area. It also confirmed low soil fertility as the main constraint. As iterated, for maize production, low soil nitrogen is one of the major causes for low soil fertility. The research confirmed that maize farmers in the districts preferred maize with specific traits including low $\mathrm{N}$ tolerance, drought tolerance, good storability, disease and insect resistance and with little need for inputs. Additionally, they prefer slender cobs, light in weight with lots of grains. Additionally, farmers are willing to adopt low $\mathrm{N}$ tolerant hybrid maize varieties if the price of seeds is affordable and after observing their performance on-farm.

It is imperative to breed for maize hybrids tolerant to low soil nitrogen, as this will mitigate challenges farmers face with unavailability and high cost of fertilizer. There is urgent need to encourage the adoption of hybrid varieties which are more tolerant to low soil fertility and are responsive to applications of inputs to raise maize productivity. This will require varieties significantly superior to those currently in use, an effective seed production and delivery system, and mechanisms to overcome some of the market failures that discourage technology adoption. There will also be the need to integrate targeted farmers as well as farmer- preferences and concerns in low fertility / low $-\mathrm{N}$ - related maize breeding programmes to ensure their success and also smooth and sustainable adoption of the hybrid seeds for increased production.

\section{Acknowlegdement}

The authors are grateful to Alliance for a Green Revolution in Africa (AGRA) for sponsoring this study. Thanks to the Director (Professor Eric Y. Danquah) and staff of West Africa Centre for Crop Improvement (WACCI), University of Ghana for your support. Staff of CSIR-Crops Research Institute and the extension agents at Ministry of Food and Agriculture.

\section{References}

Adu, R. (2012). Assessment of The Potential of Reclaimed Mined Land for Agricultural Production. Masters dissertation from Kwame Nkrumah University of Science and Technology, pp. 1. Retrieved from the University library, http://hdl.handle.net/123456789/5877

Banziger, M., \& M, Cooper. (2001). Breeding for low input conditions and consequences for participatory plant breeding: Examples from tropical maize and wheat. Euphytica, 122, 503-519. https://doi.org/10.1023/A:1017510928038

De Vries, J., \& Toenniessen, G. H. (2001). Securing the harvest: Biotechnology, breeding and seed systems for African crops. CAB International, Wallingford, UK.

Dogor, M. M. K. (2013) The effect of fertilizer formulation on yield components and yield of hybrid maize (Zea mays L.) varieties in the Guinea savannah zone of Ghana. (Masters dissertation from University of Ghana Pp 11) Retrieved from http://ugspace.ug.edu.gh/

Lafitte, H. R., \& Edmeades, G. O. (1994). Improvement for tolerance to low soil nitrogen in tropical maize II. Grain yield, Biomass production, and N accumulation, Field Crops Research, 39, 15-25, https://doi.org/10.1016/0378-4290(94)90067-1

Logah, V., Sarfo, E. Y., Quansah, C., \& Danso, I. (2010). Soil microbial biomass carbon, nitrogen, and phosphorus dynamics under different amendments and cropping systems in the semi-deciduous zones of Ghana. West African Journal of Applied Ecology, 17, 121- 133.

Morris, M. L., Tripp, R., \& Dankyi, A. A. (1999). Adoption and Impacts of Improved Maize Production Technology: A Case Study of the Ghana Grains Development Project. Economics Program Paper 99-01. Mexico, D.F.:CIMMYT

Nkonya, E. M., \& Featherstone, A. M. (2001). Cross-pollinated crop variety adoption studies and seed recycling: the case of maize in Tanzania. Eastern African Journal of Rural Development, 17, 25-34.

Odendo, M., De Groote, H., Odongo, O., \& Oucho, P. (2002). Participatory Rural Appraisal of Farmers' Maize Selection Criteria and Perceived Production Constraints in the Moist Mid altitude Zone of Kenya. IRMA Socio-Economic Working Paper No. 02-01. Nairobi, Kenya: CIMMYT and KARI.

Ragasa, C., Dankyi, A., Acheampong, P., Wiredu, A. N., Chapo-To, A., Asamoah, M., \& Tripp, R. (2013). Patterns of adoption of improved maize technologies in Ghana. Ghana strategy support programme. International Food Policy Research Institute. 
Sperling, L., Ashby, J. A., Smith, M. E., Weltzien-R. E., \& Mcguire, S. (2001). A framework for analyzing participatory plant breeding approaches and results. Euphytica, 122, 439-450. https://doi.org/10.1023/A:1017505323730

Tripp, R., \& Mensah-Bonsu, A. (2013). Ghana's Commercial Seed Sector: New Incentives or Continued Complacency? Ghana Strategy Support Program Working Paper 32. Washington, DC: International Food Policy Research Institute. WABS Consulting Ltd. 2008. "Draft Report: Maize Value Chain Study in Ghana, Enhancing Efficiency and Competitiveness," WABS Consulting Ltd. December 2008.

Wekesa, E., De Groote, H., Ndungu, J., Chivatsi, W., Mbutha, P., Hadullo, L., Odhiambo, J., \& Ambajo, G. (2003). Participatory rural appraisals for insect resistant varieties in the Coastal lowlands, Kenya. IRMA socio-economic working paper 03-01.

Wolfe, D. W., Henderson, D. W., Hsiao, T. C., \& Alvio, A. (1988). Interactive water and nitrogen effects on maize. II. Photosynthetic decline and longevity of individual leaves. Agronomy Journal, 8, 865- 870. https://doi.org/10.2134/agronj1988.00021962008000060005x

\section{Copyrights}

Copyright for this article is retained by the author(s), with first publication rights granted to the journal.

This is an open-access article distributed under the terms and conditions of the Creative Commons Attribution license (http://creativecommons.org/licenses/by/3.0/). 